\title{
Orofaciodigital syndrome type 12
}

INSERM

\section{Source}

INSERM. (1999). Orphanet: an online rare disease and orphan drug data base.

Orofaciodigital syndrome type 12. ORPHA:141327

Orofaciodigital syndrome type 12 is a rare subtype of orofaciodigital syndrome, with sporadic occurrence, characterized by cardiac (septum hypertrophy) and central nervous system abnormalities (myelomeningocele, Sylvius aqueduct stenosis, corpus callosum agenesis, vermis hypoplasia), in addition to oral, facial and digital malformations (gingival frenulae, bifid tongue, supernumerary teeth, macrocephaly, hypertelorism, pre- and postaxial polydactyly in hands, preaxial polydactyly in feet and club feet). Skeletal anomalies, such as short tibiae and central, Y-shaped metacarpals, are also associated. 